\title{
EDITORIAL
}

\section{European Curriculum Recommendations for Training in Paediatric Respiratory Medicine: one step further}

\author{
M. Gappa*, J-L. Noël\#, T. Séverin ${ }^{\#}$ and J.Y. Paton`, on behalf of the Paediatric HERMES Task Force ${ }^{+}$
}

The 2010 September issue of Breathe features the Curriculum Recommendations for Training in Paediatric Respiratory Medicine [1]; a detailed version of the 24 curriculum modules can also be found online at http://hermes.ersnet.org/. The curriculum is the result of the ongoing work of the Paediatric HERMES (Harmonised Education in Respiratory Medicine for European Specialists) Task Force. It represents the second step of the Task Force's ongoing work. The goal of the Task Force is to strengthen paediatric respiratory medicine in Europe by increasing quality and harmonising training.

The Task Force, consisting of 17 acknowledged experts in PRM, is strongly supported by the European Respiratory Society (ERS) Headquarters and an educational specialist (J. Busari). Wideranging consultation has been used throughout the development process since the Task Force took up its work in 2007. Following an online survey, which highlighted the need to update the first European syllabus in PRM [2], the core syllabus was revised and published in March 2009 [3]. The syllabus lists the knowledge considered necessary for a paediatric respiratory specialist. It is divided into 24 modules and specifies the required level of knowledge. To ensure the acceptability of the results of the Task Force's work, development of the syllabus included a modified Delphi process involving: respondents from across Europe, who voted on behalf of their respective National Societies; fellows in training from different countries; and the Task Force members themselves. The tertiary care level of training includes 21 mandatory modules and three optional modules, with a specified level of competence that is to be achieved (table 1). The core syllabus has been approved by the European Academy of Paediatrics, and since its publication it has received considerable attention on a national and an international level [4-6].

\section{Translating clinical situations into training recommendations}

The paediatric respiratory medicine (PRM) trainee is often confronted by the clinical situation of diagnosing and managing a lower respiratory tract infection in an immunodeficient child. This situation is not uncommon

\footnotetext{
*Pediatric Pulmonology and Neonatology, Medizinische Hochschule Hannover, Hannover, Germany.

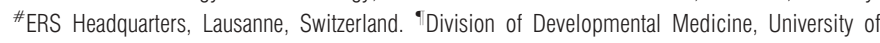
Glasgow, Glasgow, UK. ${ }^{+}$A full list of the members of the Paediatric HERMES Task Force can be found in the Acknowledgements.
}

CORRESPONDENCE: M. Gappa, Pediatric Pulmonology and Neonatology, Medizinische Hochschule Hannover, Carl-Neuberg-Str 1, Hannover, D-30625, Germany. E-mail: monika.gappa@marienhospital-wesel.de in practice. It is also a sample clinical situation in the new European Curriculum Recommendations for Training in Paediatric Respiratory Medicine. The curriculum module "Diagnosis and management of respiratory infections in high-risk situations in acute and chronic lung infections" hasbeen expanded to include the following learning outcomes: knowledge, skills, and attitudes and behaviour. In order to guide the trainee and provide them with adequate clinical exposure, the curriculum recommends that they document a minimum of five cases each of lung infection in immunocompromised and other high-risk patients, as well as keeping a portfolio. The curriculum further recommends that the trainee be assessed using case-based discussion $(\mathrm{CbD})$. The mentor of the trainee can then have a quick look at the Assessment Toolbox of the curriculum, which aims to introduce modern assessment tools, and contextualise it in the PRM scenario.

Perhaps the greatest challenge has been how to translate the syllabus into practice. From the start, it was clear that a curriculum had to be developed that would include the knowledge and skills required for clinical competence in the specialty, but that would also provide recommendations as to how each specific topic should be taught, learned and assessed. The result is: 1) the curriculum rationale that can be found in Breathe [1]; 2) curriculum recommendations for each of the 24 modules in the revised syllabus (which can be found online at http://hermes.ersnet.org/); 3) an Assessment Toolbox that details the most commonly recommended methods by which trainees may be assessed and supervised during training. This is complemented by a Paediatric Educational Track, developed by the ERS School, which lists ERS online resources according to the way in which they relate to the respective modules (available online at http://www.ers-education.org/). Thus, the core syllabus defines the knowledge and skills that a PRM trainee needs to acquire, while the curriculum provides learning outcomes, minimum training requirements, and assessment tools for key clinical situations within PRM training.

Throughout the process, the Task Force was mindful of the challenge of promoting state-of-the-art education in PRM, whilst taking into account the wide range of standards that currently exist across Europe. All items in the curriculum have been discussed by the Task Force members and the national respondents, and it is hoped that the result will be acceptable to all, even if the standards are aspirational for some. We hope that the Assessment Toolbox will be particularly useful to those 


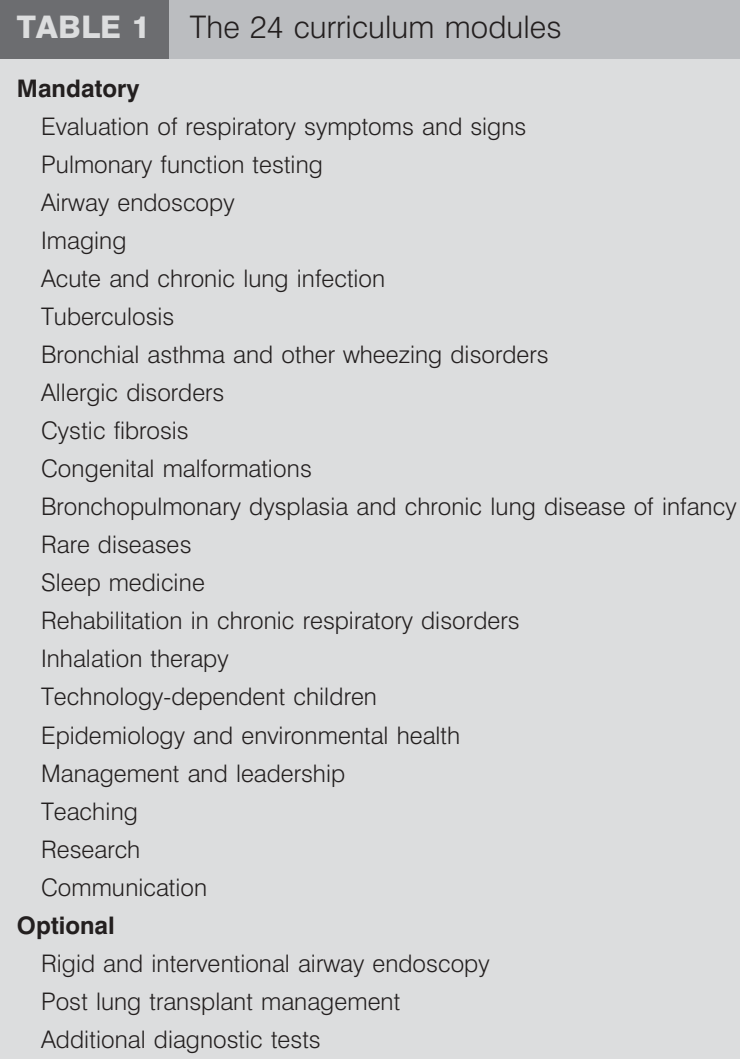

providing training, and we have been careful to describe the tools in a language that is understood not only by educational experts but also by those who will use them in everyday training.

In addition to the proposed assessment tools, core knowledge in PRM may be assessed through multiple choice questions. Following the example of the adult respiratory medicine core syllabus [7, 8], the first written European Examination in PRM is being developed. With the help of educational experts, a subcommittee of the Task Force is now preparing multiple choice questions for inclusion in the examination. The first sitting of this European Examination is planned for the 2011 ERS Congress in Amsterdam. Registration for the exam will open shortly; visit http://hermes.ersnet.org/ for updates.

Following set up of the exam, the Task Force will focus on the introduction of an accreditation system for training centres and facilitation of the development of training networks throughout Europe. This is an important milestone on the journey towards harmonised education in PRM; it is also expected to be the most difficult. Accreditation will involve a centrevisitation programme, which will not only be time consuming but is also likely to be rather costly. In addition, the national authorities will retain responsibility for training requirements and implementation of standards; it remains to be seen how fast the Task Force activities will lead to changes in national policies. However, PRM is a small subspecialty. Providing an up-to-date and practically-orientated European curriculum and exam will offer a sound basis to work from, which is likely to be appreciated within individual states.

The Task Force believes that the curriculum will prove invaluable to the future of PRM in Europe. The documents incorporate modern educational views, are clinically relevant and comprehensive, and it is hoped that they will be well accepted by our colleagues. With the curriculum publication, Paediatric HERMES has taken a step closer towards a European Specialist in Paediatric Respiratory Medicine.

\section{STATEMENT OF INTEREST}

A statement of interest for J.Y. Paton can be found at www.erj. ersjournals.com $/ \mathrm{misc} /$ statements.dtl

\section{ACKNOWLEDGEMENTS}

The members of the Paediatric HERMES (Harmonised Education in Respiratory Medicine for European Specialists) Task Force are as follows: E. Baraldi (Dept of Pediatrics, Unit of Respiratory Medicine and Allergy, University of Padova, Padova, Italy), A. Bush (Imperial College London and Royal Brompton and Harefield NHS Foundation Trust, London, UK), K-H. Carlsen (Dept. of Paediatrics, Oslo University Hospital, Oslo, Norway), J. de Jongste (Dept of Pediatrics, Erasmus University Medical Center, Sophia Children's Hospital, Rotterdam, The Netherlands), E. Eber (Klinische Abteilung für Pulmonologie und Allergologie, Univ. Klinik für Kinder und Jugendheilkunde, Medizinische Universität Graz, Graz, Austria), B. Fauroux (Pediatric Pulmonology and Research Unit INSERM UMR S938, Armand Trousseau Hospital, Pierre et Marie Curie University, Paris, France), S. McKenzie (Barts and the London NHS Trust, The Royal London Hospital, London, UK), P. Pohunek (Division of Paediatric Respiratory Medicine, Paediatric Dept, Charles University, 2nd Medical Faculty and University Hospital Motol, Praha, Czech Republic), K. Priftis (Third Dept of Pediatrics, University of Athens School of Medicine, Attikon University Hospital, Athens, Greece), R. Primhak (Sheffield Children's Hospital, Sheffield, UK), J. Wildhaber (Paediatrics, Hospital Fribourgeois, Fribourg, Switzerland), M. Zach (Respiratory and Allergic Disease Division, Paediatric Dept, Medical University of Graz, Graz, Austria) and Z. Zivkovic (Bronchology Dept, Children's Hospital for Lung Diseases and Tuberculosis Medical Center "Dr Dragisa Misovic", Belgrade, Serbia). J. Busari (Dept of Educational Development and Research Faculty of Health, Medicine and Life Sciences, Maastricht, and Pediatric Residency Program and Dept of Pediatrics, Atrium Medical Center, Heerlen, The Netherlands) is the educational specialist.

\section{REFERENCES}

1 Gappa M, Noël J-L, Séverin T, et al. Paediatric HERMES: European Curriculum Recommendations for Training in Paediatric Respiratory Medicine. Breathe 2010; 7: (In press).

2 Zach MS. Paediatric respiratory training in Europe: syllabus and centres. Eur Respir J 2002; 20: 1587-1593.

3 Gappa M, Noël J-L, Séverin T, et al. Paediatric HERMERS: a European Syllabus in Paediatric Respiratory Medicine. Breathe 2009; 5: 236-247.

4 Gappa M. Paediatric respiratory medicine: the European perspective. Paediatr Respir Rev 2010; 11: 64-65.

5 Gappa M, Ferkol T, Kovesi T, et al. Pediatric respiratory medicine: an international perspective. Pediatr Pulmonol 2010; 45: 14-24.

6 Gappa M, Paton J, Baraldi E, et al. Paediatric HERMES: update of the European Training Syllabus for Paediatric Respiratory Medicine. Eur Respir J 2009; 33: 464-465.

7 Loddenkemper R, Séverin T, Eiselé JL, et al. HERMES: good reasons for harmonising education and training in respiratory medicine. Eur Respir J 2006; 28: 470-471.

8 Loddenkemper R, Séverin T, Haslam PL. European curriculum recommendations for training in adult respiratory medicine: crossing boundaries with HERMES. Eur Respir J 2008; 32: 538-540. 